\title{
Spheroidisation of metal powder by pulsed electron beam irradiation
}

\author{
J.W. Murray ${ }^{a *}$, M. Simonellib , A. Speidel ${ }^{\mathrm{a}}$, D.M. Grant ${ }^{\mathrm{c}}$, A.T. Clare $^{\mathrm{a}, \mathrm{d}}$ \\ aAdvanced Component Engineering Laboratory (ACEL), Faculty of Engineering, University \\ of Nottingham, Nottingham, NG7 2RD, U.K. \\ ${ }^{b}$ Centre for Additive Manufacturing, Faculty of Engineering, University of Nottingham, NG7 \\ 2RD, UK \\ 'Advanced Materials Research Group, Faculty of Engineering, Faculty of Engineering, \\ University of Nottingham, NG 7 2RD, UK \\ ${ }^{\mathrm{d}}$ Department of Mechanical, Materials and Manufacturing Engineering, Faculty of Science \\ and Engineering, University of Nottingham China, 199 Taikang East Road, University Park, \\ Ningbo 315100, China
}

*james.murray@nottingham.ac.uk B49 Advanced Manufacturing Building, Jubilee Campus, University of Nottingham, NG8 1BB, UK. Tel. $+447816189239$

\begin{abstract}
A new powder spheroidisation process has been demonstrated using a large-area, pulsed electron beam technique. This was used to dramatically improve the surface morphology of Stellite 6 metal powder. Powder surface asperities up to $20 \mu \mathrm{m}$ size can be eliminated by melting and incorporation into the near-surface of the particle. Surface finish is significantly improved. Agitation and rotation of particles due to a beam-induced stress wave enables the irradiation of multiples sides of particles, resulting in uniformly smoothed particles after sufficient pulses. Elemental analysis revealed no measurable contamination as a result of the process. Transmission electron microscopy showed a dense layer is produced within a zone up to $3 \mu \mathrm{m}$ beneath the surface, with a substantially reduced grain size from ca. $2 \mu \mathrm{m}$ diameter in the bulk to ca. $40 \mathrm{~nm}$. Elemental homogenisation also was accompanied by grain refinement. The irradiated Stellite 6 showed a reduced basic flowability energy (583 mJ compared to $627 \mathrm{~mJ}$ for the untreated), explained by reduced particle-particle cohesion and interlocking, and an increased conditioned bulk density of $4.57 \mathrm{~g} / \mathrm{ml}$ compared to $4.33 \mathrm{~g} / \mathrm{ml}$ due to satellite/asperity reduction.
\end{abstract}

Keywords: powder; spheroidisation; surface treatment; electron irradiation; flowability

\section{Introduction}

Powder quality, in particular angularity and sphericity, can influence their ability to be manufactured via additive manufacturing and other processing techniques. Non-spherical powders can be produced from the various powder manufacturing techniques. Gas 
atomisation and water atomisation can produce metal powders which are agglomerated and have satellites [1]. Under turbulent conditions of the atomisation process, fine particles move faster and solidify more quickly than coarse particles, thereby attaching to the larger particle molten or semi-molten surfaces [2]. This results in agglomerate or satellite formation effectively via sintering or welding. In the case of ceramics particles often remain in the solid phase through simple crushing or grinding, generating powders which are typically irregular.

Non-spherical, satellited powders can limit processing in materials manufacturing, such as thermal/cold spray coating, laser cladding, powder metallurgy and additive manufacturing due to reduced flowability and packing density. Poor flowability can inhibit delivery through feeding systems such as in thermal spraying systems [3]. Low packing density limits the uniformity and density of parts made by additive manufacturing processes, and poor flowability leads to problems in powder spreading in powder bed fusion processes including selective laser melting [4] and electron beam melting. Tungsten parts made by SLM have shown reduced cracking and porosity from spheroidised powder compared with raw powder [5]. It has also been shown that in SLM, laser absorptivity of powder layers can increase for powders which have been spheroidised likely explained by increased packing density, e.g. from 5.39 to $11.0 \mathrm{~g} / \mathrm{cm}^{3}$ [6]. Particle cohesiveness has also been shown to have a strong influence on powder bed packing density, by up to two orders of magnitude compared to gravity, particle size dependent, prior to a powder bed fusion process [7]. Particle cohesiveness can be defined as a force between particles tending to bond one particle to its neighbour. Such a force may be a combination of electrostatic charges, surface energies and Van der Waals forces.

Currently, spheroidisation of powders is typically performed by plasma or flame spheroidisation, which remelts powders entirely in a plasma, producing particle sizes which differ from the original powder. For example, in radio-frequency (RF) plasma spheroidisation of Ti-6Al-4V powder, powder size distribution was significantly altered by the process, in particular with a much smaller proportion of smaller range powders present after spheroidisation [8]. In addition, RF plasma spheroidisation causes the structure to be modified, and contamination can be introduced by the process including oxide formation, for example Ti oxides in $\mathrm{Nb}-\mathrm{Ti}$ alloy powders [9]. When ceramics and glass particles are required to be spherical, for higher temperature glasses and ceramics, oxygen-acetylene flame spheroidisation is required [10-12], in which spherical powders are made from highly 
angular powders. Again the process results in a significantly modified particle size distribution, in particular with smaller particles being eliminated. Formation of porosity due to gas entrapment is also known to occur in flame spheroidisation [12].

In the present work, low-energy, high current pulsed electron beam irradiation (LHEB) is investigated as a novel technology to incrementally, with each pulse, smoothen metal powders without generating porosity or introducing contamination. The process generates low-energy (10-40 keV), high current (10-25 kA) electron beams which has been used to modify the near-surface of materials [13]. A high energy-density $\left(1-27 \mathrm{~J} / \mathrm{cm}^{2}\right)$ beam is applied over a short pulse duration, typically 0.8-3 $\mu$ s, releasing beam energy within a thin layer $(<10 \mu \mathrm{m})$, resulting in melting of material. Very high heating and cooling rates are produced by the process (up to $10^{9} \mathrm{~K} / \mathrm{s}$ ), yielding fine grain sizes [14,15], and metastable phases [16]. As a result, the majority of literature involving the use of LHEB involves microstructural investigation of modified materials and accompanying modified functional properties $[17,18]$.

Pulsed electron beam irradiation is well known to be able to reduce roughness of materials via rapid melting and quenching [13]. However, the elimination of asperities/satellites on powders has until now not been demonstrated, although deburring of micro holes has been investigated [19]. In the work presented here we explore the potential of LHEB to reduce asperities and aspect ratio of three metal powder particle types to produce near spherical particles from angular particles without the need to atomise from the melt or flame spheroidise them. LHEB, given its ability to uniformly modify a large area of material in line of sight of the beam, with sufficient agitation of powder, may offer a practical method for processing practically useful amount of powder suitable for the high-value additive manufacturing industry. In addition, its ability to effectively modify all faces of a powder particle is assessed, combined with flowability testing on metal powders before and after irradiation, powder size distribution and near-surface material characterisation.

\section{Experimental}

\subsection{Materials}

CoCrW based Deloro Stellite 6 (melting range $1285-1410^{\circ} \mathrm{C}$ ) was chosen for its high presence of satellites on particle surfaces, as well as slight angularity and non-uniform particle sizes (see Figure 1). 


\subsection{Low-energy high-current electron beam irradiation}

A Sodick PF32A EBM machine (Japan) was used for low-energy high-current pulsed electron irradiation. A cathode (accelerating) voltage of $40 \mathrm{kV}$ and pulse numbers of 10,50 and 150 were used. Argon at a pressure of $0.05 \mathrm{~Pa}$ was used as the medium for plasma formation. A more detailed description of the workings of the machine can be found in work from the inventors of this technique, for example in [20]. Firstly a solenoid coil produces a magnetic field, at the maximum intensity of which a pulsed voltage of $5 \mathrm{kV}$ is applied to the anode and Penning discharge is initiated. After a duration of 50-100 $\mu \mathrm{s}$, the current of the Penning discharge reaches 150-170 A, and a plasma column is formed near the anode. After a delay time of 10-30 $\mu \mathrm{s}$, an accelerating voltage of up to $40 \mathrm{kV}$ with a rise time of 20-100 ns is applied to the cathode. The electric field is concentrated in a near-cathode ion layer and reaches values of up to $400 \mathrm{kV} / \mathrm{cm}$. Explosive emission takes place on the cathode causing a number of cathode spots (dense plasma clouds) to appear and emit electrons. The applied voltage is concentrated in a double-layer, between the cathode plasma and the anode plasma, in which electrons are accelerated and the beam is formed. The electron beam accelerated in the double layer is transported through the anode plasma to a collector cathode where the workpiece is placed. The diameter of the beam is $60 \mathrm{~mm}$; with a pulse-time of 0.8-3 $\mu$ s [20]. Within the $60 \mathrm{~mm}$ diameter, energy density has been shown to be uniform [21]. Beyond this diameter the beam is present but with a reduced energy density. In addition, surfaces treated at angles of up to $75^{\circ}$, i.e. almost parallel to the beam, have shown to be subject to almost the same smoothing effect as surfaces perpendicular to the beam [21]. A cathode voltage of 40 $\mathrm{kV}$ was used in all experiments, which translates to an energy density of $27 \mathrm{~J} / \mathrm{cm}^{2}$. Irradiation takes place at a vacuum level of $0.05 \mathrm{~Pa}$. Prior to irradiation, the powder was spread over an area of $60 \mathrm{~mm}$ diameter, the approximate width of the beam under which it is considered uniform in energy density. The powder was spread and distributed loosely, uniformly and without adhesive on a stainless steel powder bed like workpiece prior to irradiation. This small amount was chosen as it resulted in approximately a single layer of particles being exposed to the beam. A metal workpiece was used as a good electrical and thermal conductor. The steel workpiece was not moved under treatment. At maximum cathode voltage, given the melting point is expected to be reached [22], a minor level of attachment/alloying of some particles with the substrate was noted. This may be reduced in future work using a high melting point or high thermal conductivity powder bed. Practically, 
achieving the vacuum took 10 minutes, with approximately 11 seconds delay between each pulse, therefore 150 pulse treatment took approximately 27 minutes after attaining vacuum.

\subsection{Electron microscopy and focus variation microscopy}

Microscopy of particles was performed by attachment of powders to a sticky carbon pad as used in standard electron microscopy. Scanning electron microscopy (SEM) was performed using a JEOL 6490LV. Transmission electron microscopy was performed using a JEOL $2100 \mathrm{~F}$ operated at $200 \mathrm{kV}$ attached with an Oxford Instruments INCA X-ray microanalysis system used for energy-dispersive X-ray (EDX) analysis. A TEM lamella was prepared using an FEI Quanta 200 3D focused ion beam (FIB) from a Stellite 6 particle subject to 150 pulses at $40 \mathrm{kV}$. Transfer of the sample to the TEM support grid was achieved using an Omniprobe in-situ nanomanipulator. Powder roughness was appraised using an Alicona Infinite Focus focus variation microscope. Topography maps were taken of 15 random particles of Stellite 6 powder before and after irradiation. An $80 \mu \mathrm{m}$ diameter hemispherical area was extracted from the dataset and the spherical form was removed and converted to a circular area. Waviness was also removed from the data using an $8 \mu \mathrm{m}$ threshold prior to ISO $25178 \mathrm{Sa}$ and $S z$ roughness calculation. $S a$ is the difference in height of each point compared to the arithmetic mean of the surface. $S z$ is the difference in height between the highest peak and the deepest valley. Powder rheometry tests were performed using a Freeman FT4 powder rheometer, using $25 \mathrm{ml}$ of each powder type. Both powder types were passed through a 125 $\mu \mathrm{m}$ sieve to remove agglomerates.

\subsection{Powder flowability and size distribution}

A Freeman FT4 powder rheometer was used to evaluate powder flow properties. The principle of the device is that a twisted blade is forced through a powder along a predetermined helical path. Flow energy is calculated from the work done to move the blade from the top to the bottom of the vessel, after an initial conditioning cycle, in which the powder establishes a uniform and reproducible state. Seven identical test cycles, each involving conditioning and testing, are performed. After these seven tests, the blade tip speed is reduced from 100 , to 70,40 and $10 \mathrm{mms}^{-1}$, to evaluate the sensitivity of the power to flow rate. Basic flowability energy (BFE) is the stabilised flow energy that represents the energy needed to displace a conditioned powder sample during downwards testing, and is equal to the energy of test 7 , i.e. the final repeat flowability test at constant tip speed. Powder size data was measured by manual measurement of between 600 and 650 individual powder areas 
imaged by SEM. Diameters were calculated via the equation for area of a circle, and therefore particles were modelled as spheres for the purposes of simple comparison. A manual measurement method for powder size measurement was elected over a laser diffraction strategy given the large volume required for the latter process, not practically possible in the current iteration of the irradiation process, as well as the sacrificial nature of the diffraction process.

\section{Results}

\subsection{Powder morphology}

A small amount of Stellite 6 powder ( $2 \mathrm{~g}$ ) was spread on a stainless steel workpiece prior to irradiation. Figure 1 shows low and high magnification SEM images of as-received powder compared to powder subject to pulsed electron irradiation at both 50 and 150 pulses at $40 \mathrm{kV}$. 

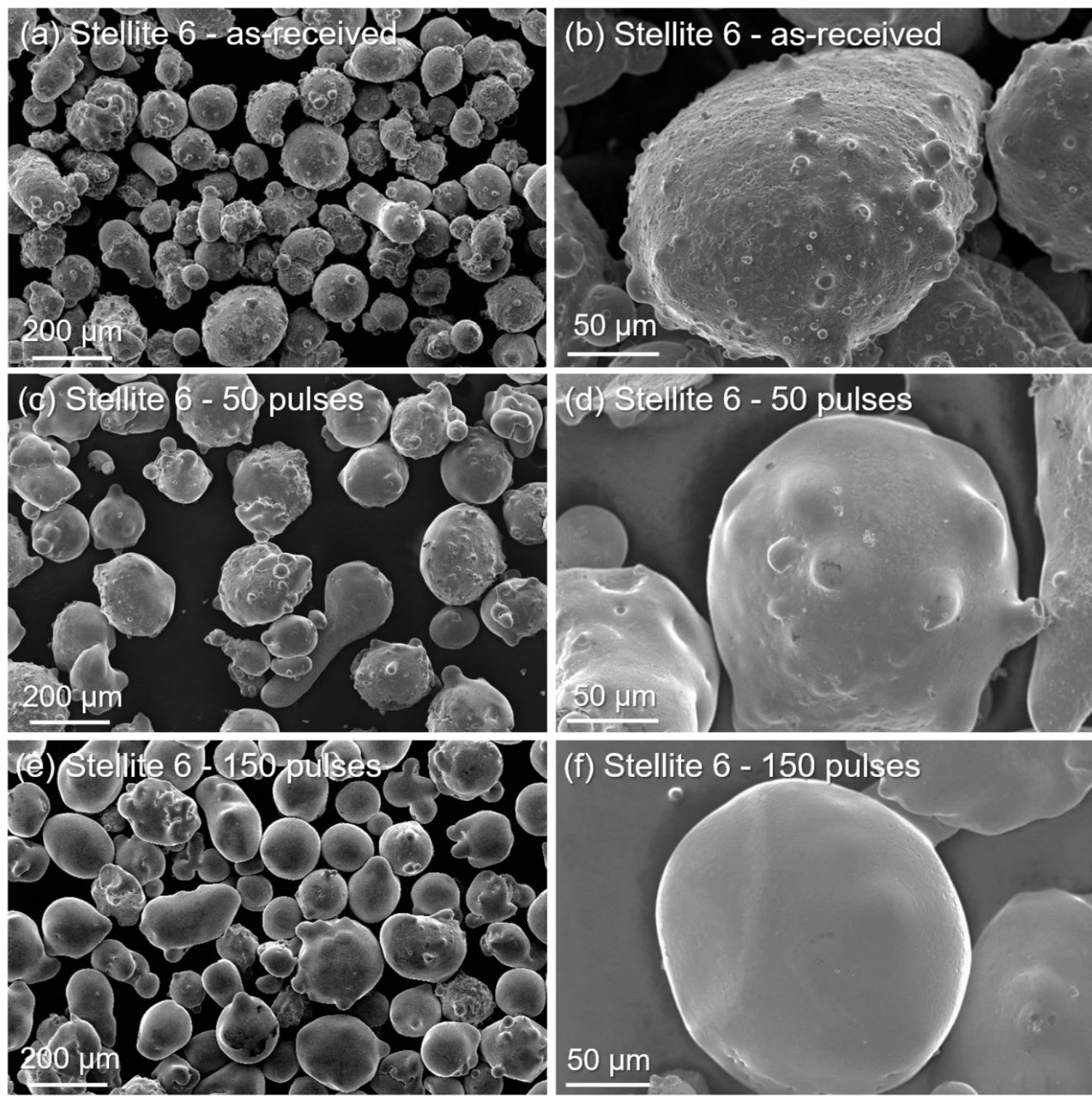

Figure 1 SEM images at low and high magnification of Stellite 6 powder subject to 50 pulse and 150 pulse irradiation at $40 \mathrm{kV}$, revealing polishing and satellite elimination.

The as-received powders exhibiting surface roughness and significant asperity and satellite density can be seen in Figure 1. After treatment with 50 pulses, the micro-scale texture was generally eliminated and many of the smaller asperities and satellites were smoothened. A non-uniformity was also seen to many of the particles, with many remaining only partially smoothed, or not smoothed on all sides. Under irradiation at 150 pulses, a large proportion of particles were entirely smoothened and spheroidised. In both the high and low magnification images in Figure 1 a high degree of sphericity and high proportion of smoothed powders can be seen. To quantify the smoothing effect seen via SEM, $S a$ and $S z$ values were calculated from 15 random particles of Stellite 6 before and after 150 pulse irradiation, shown in Table 1, described in section 2.3. 
Table 1 Mean $S a$ and $S z$ roughness values for as-received and 150 pulse irradiated Stellite 6. Error is standard error of the mean.

\begin{tabular}{|c|c|c|}
\hline & Sa (nm) & Sz (nm) \\
\hline As-received & $218 \pm 28.7$ & $9302 \pm 1815$ \\
\hline Irradiated & $95.7 \pm 6.6$ & $2923 \pm 299$ \\
\hline
\end{tabular}

The mean $S a$ value was reduced by over half to $95.7 \mathrm{~nm}$ from $218 \mathrm{~nm}$, with a standard error of 6.6, confirming a significant smoothing phenomenon. $S z$ value was similarly reduced by a factor of three to $2923 \mathrm{~nm}$ from $9302 \mathrm{~nm}$ confirming reduction in asperity heights.

\subsection{Cross-sectional TEM}

To elucidate the structure, density, depth and composition of the remelted zone in the nearsurface of successfully spheroidised particles, cross-sectional TEM analysis was performed on a typical spheroidised particle of Stellite 6 after 150 pulse irradiation. Cross-sectional TEM was also used to examine in more detail the near-surface composition. The sample for TEM was prepared by FIB milling and extraction of a 200 nm thick lamella from a particle subject to $40 \mathrm{kV}, 150$ pulse irradiation. The TEM sample prior to extraction and thinning is shown in Figure 2 (b), and scanning TEM images, along with a diffraction pattern of modified zone, are shown in Figure 2 (a), (c) and (d). 


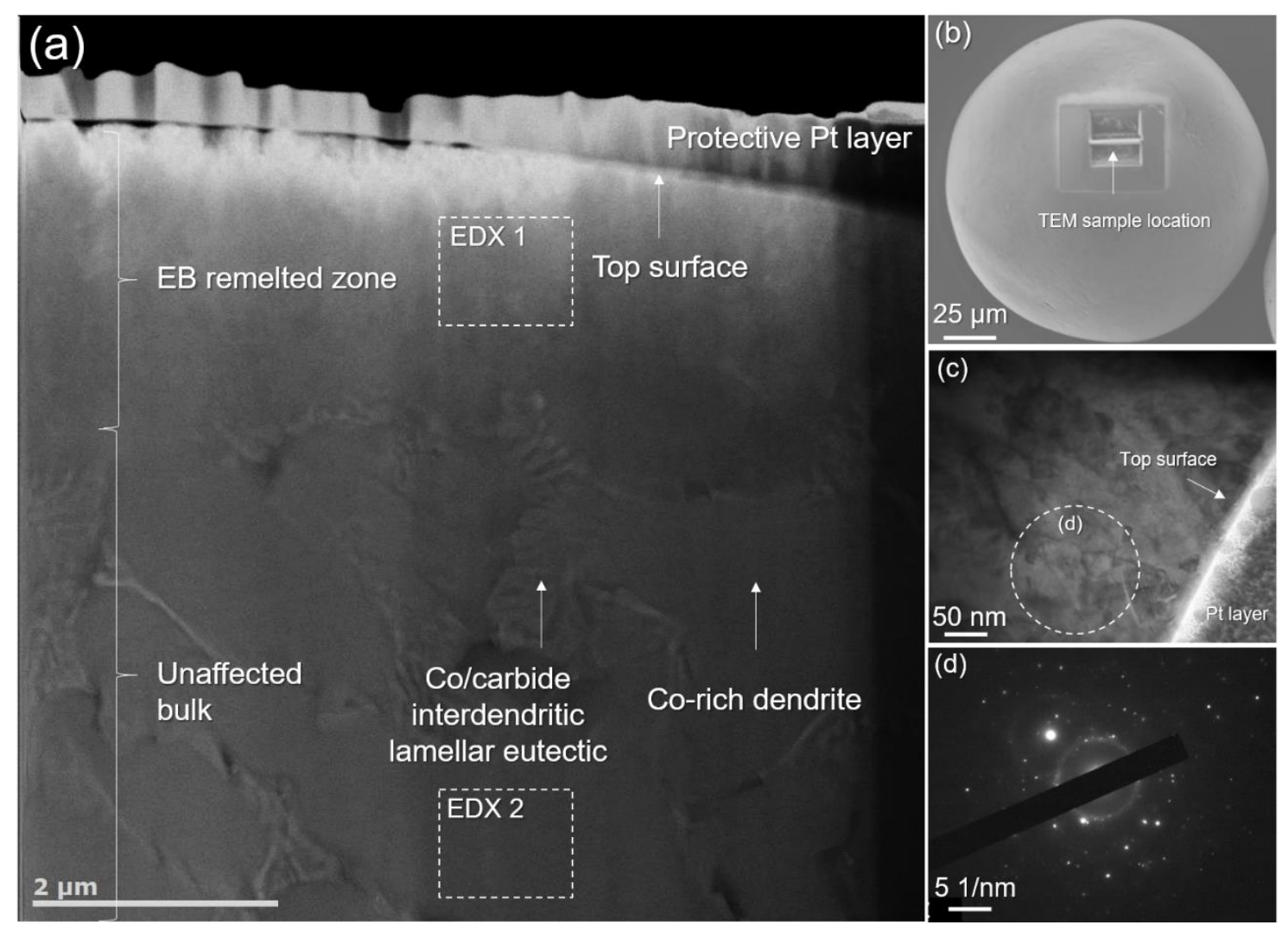

Figure 2 (a) DFSTEM cross-sectional image of Stellite 6 powder irradiated by 150 pulses at $40 \mathrm{kV}$, (b) SEM image of TEM lamella on spheroidised powder prior to extraction, (c) BFTEM image of near surface region and (d) diffraction pattern was selected area highlighted in (c)

In Figure 2 (a), the smooth top surface can be seen beneath the protective platinum layer. An interface between a microstructurally modified zone and the bulk can be seen between 2 and $3 \mu \mathrm{m}$ beneath the top surface. The distinctive Stellite bulk can be identified by the large Corich FCC grains, as well as a lamellar-like mixture of the $\mathrm{FCC}$ phase and $(\mathrm{Co}, \mathrm{Cr}, \mathrm{W}){ }_{7} \mathrm{C}_{3}$ carbides [23]. Figure 2 (c) shows a bright field TEM image of a near-surface region. Smaller grains of approximately $40 \mathrm{~nm}$ size can be seen. A SAED pattern was taken from a region of $150 \mathrm{~nm}$ diameter and is shown in Figure 2 (d). Polycrystalline rings are present indicating a random orientation and grain size throughout the thickness of well below $150 \mathrm{~nm}$.

EDX analysis was performed at two regions labelled in Figure 2 (a), with data shown in Table 3. EDX 1 shows an increased W, Cr, C, Si and Mo level compared to the single grain analysed in EDX 2, consistent with intermixing and elemental/phase homogenisation.

Table 3 EDX composition data for regions labelled in Figure 2. Error is given as standard deviation. 


\begin{tabular}{|c|c|c|}
\hline Element & $\begin{array}{c}\text { Near surface } \\
\text { EDX 1 }\end{array}$ & Bulk EDX 2 \\
\hline Co & $55.92 \pm 0.09$ & $61.04 \pm 0.05$ \\
\hline Cr & $30.34 \pm 0.06$ & $27.70 \pm 0.04$ \\
\hline W & $7.43 \pm 0.08$ & $5.49 \pm 0.04$ \\
\hline Fe & $3.11 \pm 0.03$ & $3.43 \pm 0.02$ \\
\hline C & $0.86 \pm 0.02$ & $0.58 \pm 0.01$ \\
\hline Mn & $0.79 \pm 0.03$ & $0.79 \pm 0.02$ \\
\hline Si & $0.78 \pm 0.02$ & $0.39 \pm 0.01$ \\
\hline Mo & $0.66 \pm 0.06$ & $0.44 \pm 0.04$ \\
\hline O & $0.12 \pm 0.03$ & $0.13 \pm 0.01$ \\
\hline
\end{tabular}

\subsection{Particle size distribution}

A larger volume of powder ( $25 \mathrm{ml}$ total) was prepared for particle size distribution and flowability testing by repeat processing of powder at $40 \mathrm{kV}, 150$ pulses. Given the absence of large-scale agitation of the powders between shots, some powders formed agglomerates which were directly facing the beam under 150 pulses. Therefore all powders were passed through a $125 \mu \mathrm{m}$ sieve to remove agglomerates. Figure 3 shows histograms of particle sizes measured from the Stellite 6 powder before and after irradiation, and Table 4 shows size data for the powders. Histogram bin size is $10 \mu \mathrm{m}$ diameter, with each bin split into two representing the two samples. 


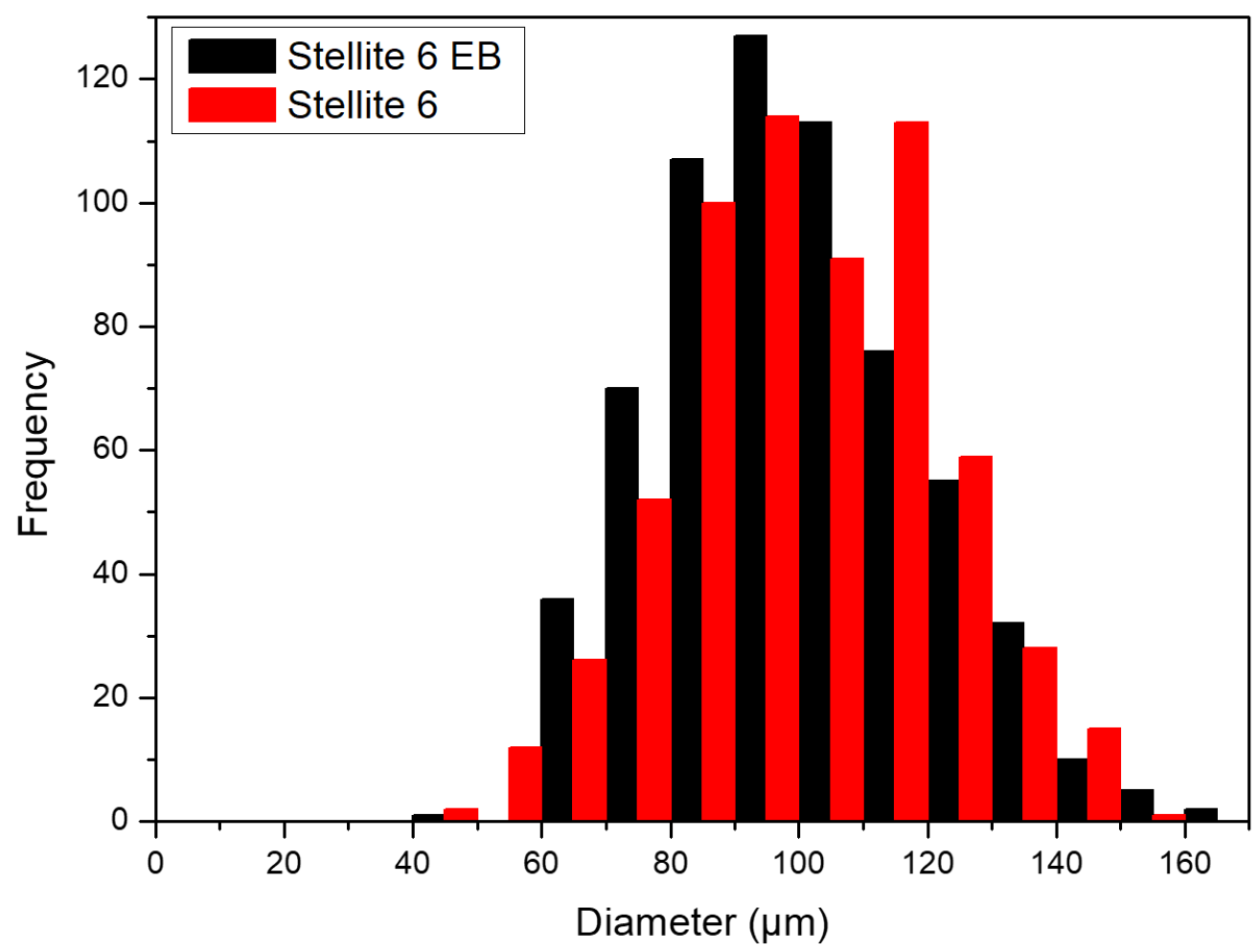

Figure 3 Particle size distribution histograms of Stellite 6 powder before and after irradiation at $40 \mathrm{kV}, 150$ pulses

Table 5 Particle size data before and after irradiation at $40 \mathrm{kV}, 150$ pulses. Error given as standard error.

\begin{tabular}{|l|c|c|c|c|}
\hline & Mean $(\boldsymbol{\mu m})$ & Median/D50 $(\boldsymbol{\mu m})$ & D90 $(\boldsymbol{\mu m})$ & D10 $(\boldsymbol{\mu m})$ \\
\hline Before & $100.7 \pm 1.2$ & 100.2 & 127.9 & 74.8 \\
\hline After & $99.8 \pm 1.5$ & 97.8 & 126.4 & 74.6 \\
\hline
\end{tabular}

From the particle size histograms and size data generally the powder size distribution was not notably affected by irradiation. This particle size data supports the evidence from TEM imaging that modification is isolated to a region of only a few $\mu \mathrm{m}$ depth, and this is also generally consistent with prior literature on the topic of LHEB.

\subsection{Flowability}

To evaluate added functionality of the treated powder, stability and variable flow rate experiments on as-received and $40 \mathrm{kV}, 150$ pulse irradiated Stellite 6 powders were conducted. Table 6 shows mean flowability metrics from 3 tests on each material. 
Table 6 Reduced basic flowability energy and increased conditioned bulk density of Stellite 6 powder after 150 pulse irradiation.

\begin{tabular}{|c|c|c|c|c|c|}
\hline Material & BFE, mJ & SI & FRI & SE, mJ/g & CBD, g/ml \\
\hline As-received & $627 \pm 6.60$ & $1.01 \pm 0.009$ & $1.01 \pm 0.005$ & $1.99 \pm 0.011$ & $4.33 \pm 0.015$ \\
\hline Irradiated & $583 \pm 18.7$ & $0.990 \pm 0.021$ & $0.990 \pm 0.006$ & $1.94 \pm 0.068$ & $4.57 \pm 0.055$ \\
\hline
\end{tabular}

The key parameter of basic flowability energy (BFE) of the Stellite 6 powder showed a statistically significant reduction. Other flow metrics of stability index, flow rate index and specific energy showed slight reductions but still within error. Of note is a significant increased conditioned bulk density (CBD) after irradiation.

\section{Discussion}

A new method for spheroidising rough or satellited powders has been demonstrated in this work using a large-area pulsed electron beam technique. Key to the usefulness of the technology is the demonstrated ability of the irradiation process to agitate/rotate powders as well as remelt their surfaces. Images of irradiation of $2 \mathrm{~g}$ of Stellite 6 powder before after 40 $\mathrm{kV}$ and 50 pulses can be seen in Supplementary Figure 1, in which the original spread of powder is clearly modified and some powder is scattered around the stainless steel powder bed. Rotation and agitation of powders without external intervention can be explained by a compressive stress wave induced by the electron beam which has been estimated as high as $400 \mathrm{MPa}$ in the case of $0.5 \mathrm{~mm}$ thin specimens [16]. In typical fixed substrates, this stress wave is constrained, transmitted through the workpiece and reflected at a lower magnitude from the back of the workpiece. In the case of unconstrained powders, this stress wave is expected to move powders against each other, ultimately causing rotation upon each pulse, and exposing other faces of the powder to subsequent pulses. Experiments using a lower pulse number of 10 were also conducted on Stellite 6 powder using $40 \mathrm{kV}$ cathode voltage, in order to further investigate the agitation and smoothing phenomenon. Figure 4 shows two particles subject to the identical 10 shot treatment but modified differently. 

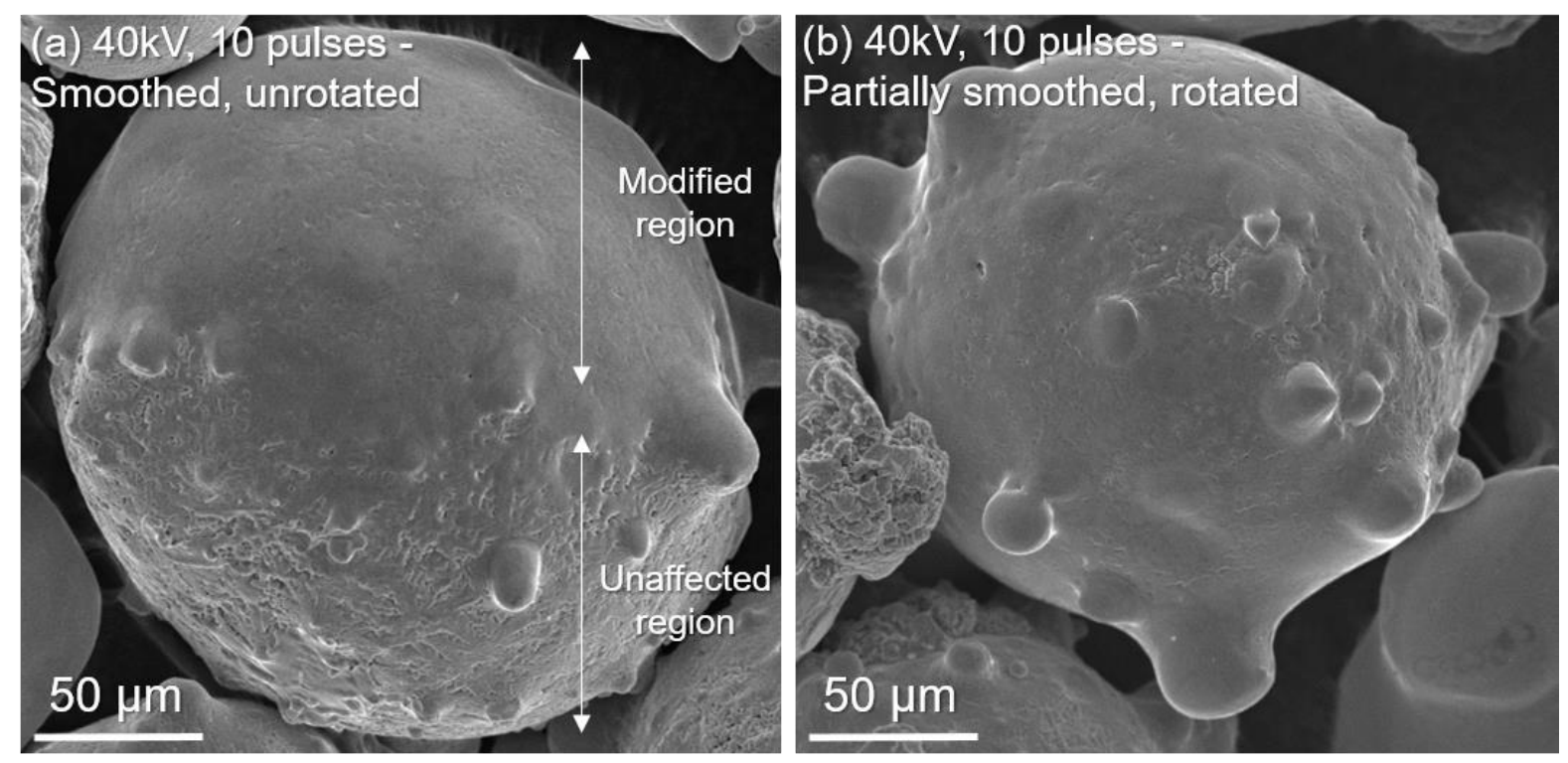

(c) Proposed rotation/smoothing mechanism

[1] Electron pulse

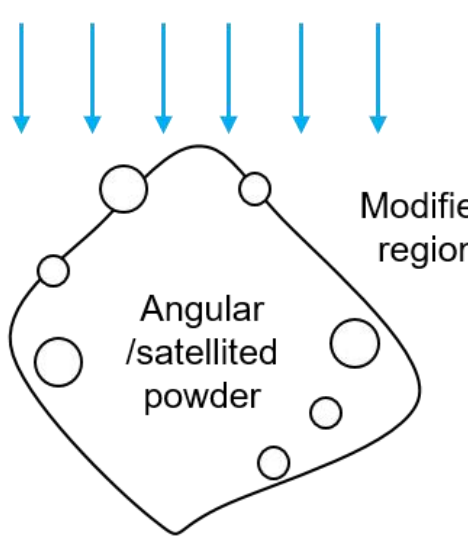

[2] Smoothing of line of sight regions + chance of rotation

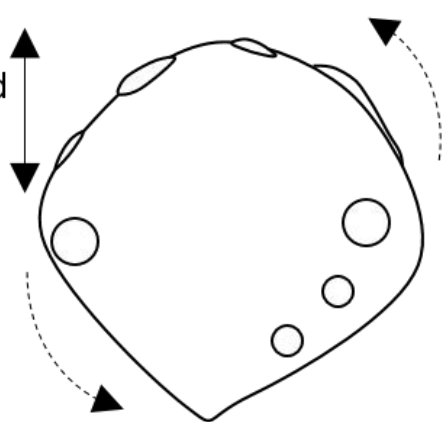

[3] Electron pulse
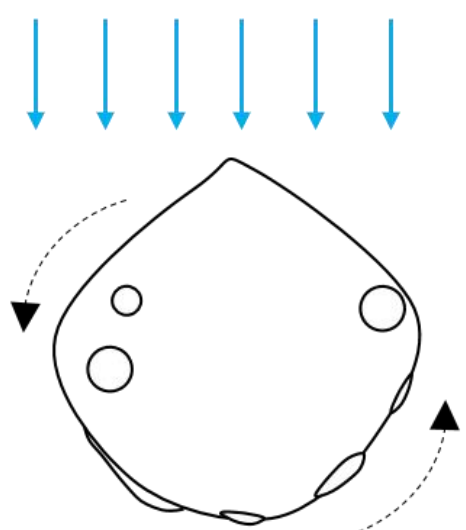

\section{Figure 4 Stellite 6 powder irradiated with 10 pulses at $40 \mathrm{kV}$ and proposed mechanism} of rotation and spheroidisation

In one case (Figure 4(a)), one side of a particle in line of sight with the beam is noticeably smoothened, and its other side appears unaffected. In the other case (Figure 4(b)), multiple sides of a particle are clearly smoothed, but to a lesser extent, with asperities still present. These two types of modification can be explained by some particles being trapped by adjacent particles, preventing movement or rotation, whereas some particles will be directly exposed to the beam with sufficient freedom to move against adjacent particles. At $40 \mathrm{kV}$ and 50 pulses, fine $<10 \mu \mathrm{m}$ satellites attached to particles were eliminated, and surface finish was notably improved. Larger satellites were mostly eliminated after 150 pulses, with the majority of particles uniformly spheroidised. From low pulse number irradiation it is also clear that dependent on material type, lower pulse numbers and hence more efficient processing can be used to successfully spheroidise powder with sufficient agitation of the powder bed. Hence 
further work should consider powder agitation between pulses to optimise this process. The number of layers of powder should be carefully selected based on ability to perform powder rotation and layer number is a key criterion for process control. Smoothing and melting of satellites into the body of the particle is the expected primary mechanism of smoothing by irradiation, particularly given the clearly remelted outer shell structure seen in TEM, however it should be noted that boiling and evaporation of material from the top surface, particularly in the case of very fine asperities, cannot be ruled out and may contribute to the smoothing effect.

Cross-sectional TEM analysis indicated that irradiation of Stellite 6 at $40 \mathrm{kV}, 150$ pulses forms a dense remelted zone with a thickness of between 2 and $3 \mu \mathrm{m}$ from the top surface. No evidence of cratering was seen, which is known to occur in irradiation of some materials [18]. A randomly oriented, fine $(<40 \mathrm{~nm})$ grain size was seen in the remelted zone. Such a microstructure is consistent with TEM studies conducted on irradiated material in prior work [14], owing to rapid solidification caused by quenching into the bulk as well as radiation from the surface. It should be noted that the microstructure of gas-atomised Stellite 6 powder has been analysed in cross-section by EBSD previously, and no outer band of finer microstructure was observed [24]. Other work on gas-atomised powder characterisation of gas-atomised metal powders also confirms that no outer shell of fine microstructure is present $[25,26]$. Therefore it can be said with some confidence that the outer band of dense material with fine microstructure seen in the irradiation spheroidised powder is as a direct result of pulsed electron irradiation remelting. Powder size distribution of the Stellite 6 powder was effectively unchanged after irradiation at $40 \mathrm{kV}, 150$ pulses compared to the as-received powder. This is explained by the isolation of the beam-modified region to only a few $\mu \mathrm{m}$ beneath the top surface.

The irradiated powder showed a notably reduced basic flowability energy (BFE) of $583 \mathrm{~kJ}$ compared to the raw powder with 627 . BFE is the energy required to establish a flow pattern in a conditioned, precise volume of powder, and is arguably the most widely accepted metric to predict the flowability characteristics of a powder and resulting performance in powder bed fabrication [27]. However, it is a complex parameter and is affected by powder properties such as size and distribution, shape, texture, stiffness, cohesivity, density but is also affected by compressibility. Reduced BFE in the case of the irradiated powder here may be explained by low particle interlocking and particle-particle cohesion. The irradiated powder also 
exhibited an enhanced conditioned bulk density, implying packing is improved after an initial conditioning by the FT4 rheometer. Increased density is explained by reduced asperity and satellite density. It should be noted that with predictable agitation of a powder bed, more uniform treatment of powders will be achieved, hence likely further improving flowability results. It is thought that further optimisation of the process will permit electron spheroidisation to become a practical method of yielding fine highly spherical and smooth powders, contamination-free, for high value additive manufacturing.

\section{Conclusions}

- Spheroidisation of metal powder particles by a large-area pulsed electron beam irradiation process has been demonstrated for the first time.

- Satellites in Stellite 6 powder can be successful smoothed and spheroidised by pulsed electron irradiation.

- $S a$ roughness is reduced from 153 to $76.5 \mathrm{~nm}$ on Stellite 6 particles subject to 150 pulsed at $40 \mathrm{kV}$ cathode voltage, accompanied by eliminated satellites and asperities.

- 10 and 50 pulses yield an incremental level of spheroidisation, whereby small satellites are eliminated and roughness greatly reduced, although larger agglomerate type satellites are not entirely eliminated.

- Powder size distribution of Stellite 6 subject to 150 pulses remains effectively unchanged.

- An outer remelted zone of between 2 and $3 \mu \mathrm{m}$ thickness was measured via crosssectional TEM analysis of a spheroidised particle subject to 150 pulses.

- The remelted zone exhibits a fine microstructure of $<40 \mathrm{~nm}$ grain size with random orientation characteristic of rapid quenching. The remelted zone is dense and uniform.

- EDX analysis in TEM and SEM confirmed no contamination occurs as a result of the irradiation process.

- Basic flowability energy was reduced from 627 to $583 \mathrm{~mJ}$ after irradiation with 150 pulses likely explained by reduced particle-particle cohesion.

- Conditioned bulk density was increased to $4.57 \mathrm{~g} / \mathrm{ml}$ after irradiation from 4.33, explained by reduced asperity/satellite density.

\section{References}

[1] A. V Krajnikov, V. V Likutin, G.E. Thompson, Comparative study of morphology and 
surface composition of $\mathrm{Al}-\mathrm{Cr}-\mathrm{Fe}$ alloy powders produced by water and gas atomisation technologies, Appl. Surf. Sci. 210 (2003) 318-328.

doi:https://doi.org/10.1016/S0169-4332(03)00150-8.

[2] S. Özbilen, Satellite formation mechanism in gas atomised powders, Powder Metall. 42 (1999) 70-78. doi:10.1179/pom.1999.42.1.70.

[3] M. Boulos, Plasma power can make better powders, Met. Powder Rep. 59 (2004) 1621. doi:https://doi.org/10.1016/S0026-0657(04)00153-5.

[4] C. Galy, E. Le Guen, E. Lacoste, C. Arvieu, Main defects observed in aluminum alloy parts produced by SLM: From causes to consequences, Addit. Manuf. 22 (2018) 165175. doi:https://doi.org/10.1016/j.addma.2018.05.005.

[5] X. Zi, C. Chen, X. Wang, P. Wang, X. Zhang, K. Zhou, Spheroidisation of tungsten powder by radio frequency plasma for selective laser melting, Mater. Sci. Technol. 34 (2018) 735-742. doi:10.1080/02670836.2017.1410955.

[6] D. Wang, C. Yu, X. Zhou, J. Ma, W. Liu, Z. Shen, Dense Pure Tungsten Fabricated by Selective Laser Melting, Appl. Sci. 7 (2017). doi:10.3390/app7040430.

[7] C. Meier, R. Weissbach, J. Weinberg, W.A. Wall, A.J. Hart, Critical Influences of Particle Size and Adhesion on the Powder Layer Uniformity in Metal Additive Manufacturing, CoRR. abs/1804.0 (2018). http://arxiv.org/abs/1804.06822.

[8] W.-H. Wei, L.-Z. Wang, T. Chen, X.-M. Duan, W. Li, Study on the flow properties of Ti-6Al-4V powders prepared by radio-frequency plasma spheroidization, Adv. Powder Technol. 28 (2017) 2431-2437. doi:https://doi.org/10.1016/j.apt.2017.06.025.

[9] Q. Li, L. Zhang, D. Wei, S. Ren, X. Qu, Porous Nb-Ti based alloy produced from plasma spheroidized powder, Results Phys. 7 (2017) 1289-1298. doi:10.1016/j.rinp.2017.03.026.

[10] H. Jin, L. Xu, S. Hou, Preparation of spherical silica powder by oxygen-acetylene flame spheroidization process, J. Mater. Process. Technol. 210 (2010) 81-84. doi:https://doi.org/10.1016/j.jmatprotec.2009.08.009.

[11] Y.W. Gu, A.U.J. Yap, P. Cheang, R. Kumar, Spheroidization of glass powders for glass ionomer cements, Biomaterials. 25 (2004) 4029-4035.

doi:https://doi.org/10.1016/j.biomaterials.2003.10.096.

[12] D. Gupta, K.M.Z. Hossain, I. Ahmed, V. Sottile, D.M. Grant, Flame-Spheroidized Phosphate-Based Glass Particles with Improved Characteristics for Applications in Mesenchymal Stem Cell Culture Therapy and Tissue Engineering, ACS Appl. Mater. Interfaces. 10 (2018) 25972-25982. doi:10.1021/acsami.8b05267.

[13] G.E. Ozur, D.I. Proskurovsky, Generation of Low-Energy High-Current Electron Beams in Plasma-Anode Electron Guns, Plasma Phys. Reports. 44 (2018) 18-39. doi:10.1134/S1063780X18010130.

[14] J.W. Murray, J.C. Walker, A.T. Clare, Nanostructures in austenitic steel after EDM and pulsed electron beam irradiation, Surf. Coatings Technol. 259, Part (2014) 465472. doi:http://dx.doi.org/10.1016/j.surfcoat.2014.10.045.

[15] V.P. Rotshtein, D.I. Proskurovsky, G.E. Ozur, Y.F. Ivanov, A.B. Markov, Surface modification and alloying of metallic materials with low-energy high-current electron beams, Surf. Coatings Technol. 180-181 (2004) 377-381.

doi:10.1016/j.surfcoat.2003.10.085.

[16] D.I. Proskurovsky, V.P. Rotshtein, G.E. Ozur, Y.F. Ivanov, A.B. Markov, Physical foundations for surface treatment of materials with low energy, high current electron beams, Surf. Coatings Technol. 125 (2000) 49-56. doi:http://dx.doi.org/10.1016/S0257-8972(99)00604-0.

[17] G. Guo, G. Tang, X. Ma, M. Sun, G.E. Ozur, Effect of high current pulsed electron beam irradiation on wear and corrosion resistance of Ti6Al4V, Surf. Coatings Technol. 
229 (2013) 140-145. doi:https://doi.org/10.1016/j.surfcoat.2012.08.009.

[18] F. Xu, G. Tang, G. Guo, X. Ma, G.E. Ozur, Influence of irradiation number of high current pulsed electron beam on the structure and properties of M50 steel, Nucl. Instruments Methods Phys. Res. Sect. B Beam Interact. with Mater. Atoms. 268 (2010) 2395-2399. doi:http://dx.doi.org/10.1016/j.nimb.2010.04.019.

[19] M. Simonelli, N.T. Aboulkhair, P. Cohen, J.W. Murray, A.T. Clare, C. Tuck, R.J.M. Hague, A comparison of Ti-6Al-4V in-situ alloying in Selective Laser Melting using simply-mixed and satellited powder blend feedstocks, Mater. Charact. 143 (2018) 118-126. doi:https://doi.org/10.1016/j.matchar.2018.05.039.

[20] A. V Batrakov, A.B. Markov, G.E. Ozur, D.I. Proskurovsky, V.P. Rotshtein, Surface alloying of metallic substrates with pre-deposited films through a pulsed electron-beam mixing, Eur. Phys. J. - Appl. Phys. 43 (2008) 283-288.

doi:doi:10.1051/epjap:2008070.

[21] Y. Uno, A. Okada, K. Uemura, P. Raharjo, T. Furukawa, K. Karato, High-efficiency finishing process for metal mold by large-area electron beam irradiation, Precis. Eng. 29 (2005) 449-455. http://www.scopus.com/inward/record.url?eid=2-s2.024944546002\&partnerID=40\&md5=1a7a717799d4a08271c0b52fd3ce3cc9.

[22] W. Peng, S. Hao, L. Zhao, J. Chen, W. Li, Formation mechanism of graphite nanospheres in W-C-Co system under high current pulsed electron beam irradiation, Mater. Lett. 244 (2019) 207-210. doi:https://doi.org/10.1016/j.matlet.2019.02.110.

[23] V. Kuzucu, M. Ceylan, H. Çelik, İ. Aksoy, Microstructure and phase analyses of Stellite 6 plus 6 wt.\% Mo alloy, J. Mater. Process. Technol. 69 (1997) 257-263. doi:https://doi.org/10.1016/S0924-0136(97)00027-7.

[24] N. Cinca, J. Guilemany, Cold Gas Sprayed Stellite-6 Coatings and their Wear Resistance, J. Mater. Sci. Eng. (2013). doi:10.4172/2169-0022.1000122.

[25] M.J. Carrington, J. Daure, V.L. Ratia, P.H. Shipway, D.G. McCartney, D.A. Stewart, Microstructural characterisation of Tristelle $5183(\mathrm{Fe}-21 \% \mathrm{Cr}-10 \% \mathrm{Ni}-7.5 \% \mathrm{Nb}-5 \% \mathrm{Si}-$ $2 \% \mathrm{C}$ in wt $\%$ ) alloy powder produced by gas atomisation, Mater. Des. 164 (2019) 107548. doi:10.1016/j.matdes.2018.107548.

[26] T. Liu, J.D. Leazer, S.K. Menon, L.N. Brewer, Microstructural analysis of gas atomized Al-Cu alloy feedstock powders for cold spray deposition, Surf. Coatings Technol. 350 (2018) 621-632. doi:10.1016/j.surfcoat.2018.07.006.

[27] M. Leturia, M. Benali, S. Lagarde, I. Ronga, K. Saleh, Characterization of flow properties of cohesive powders: A comparative study of traditional and new testing methods, Powder Technol. 253 (2014) 406-423.

doi:https://doi.org/10.1016/j.powtec.2013.11.045. 